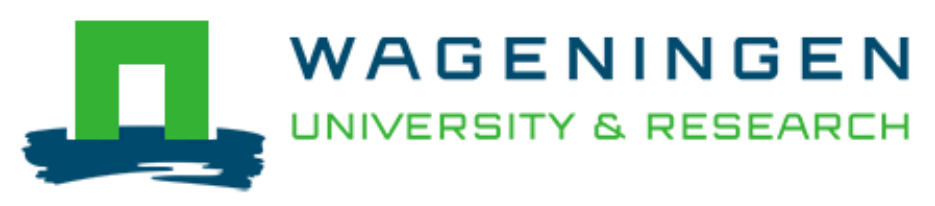

\title{
Continental-scale macrofungal assemblage patterns correlate with climate, soil carbon and nitrogen deposition
}

Andrew, C., Halvorsen, R., Heegaard, E., Kuijper, T. W., Heilmann-Clausen, J., Krisai-Greilhuber, I., ... Kauserud, H.

This article is made publically available in the institutional repository of Wageningen University and Research, under article 25fa of the Dutch Copyright Act, also known as the Amendment Taverne.

Article $25 \mathrm{fa}$ states that the author of a short scientific work funded either wholly or partially by Dutch public funds is entitled to make that work publicly available for no consideration following a reasonable period of time after the work was first published, provided that clear reference is made to the source of the first publication of the work.

For questions regarding the public availability of this article, please contact openscience.library@wur.nl.

Please cite this publication as follows:

Andrew, C., Halvorsen, R., Heegaard, E., Kuijper, T. W., Heilmann-Clausen, J., Krisai-Greilhuber, I., ... Kauserud, H. (2018). Continental-scale macrofungal assemblage patterns correlate with climate, soil carbon and nitrogen deposition. Journal of Biogeography, 45(8), 1942-1953. https://doi.org/10.1111/jbi.13374 


\title{
Continental-scale macrofungal assemblage patterns correlate with climate, soil carbon and nitrogen deposition
}

\author{
Carrie Andrew $^{1,2,3}$ (D) | Rune Halvorsen ${ }^{4}$ | Einar Heegaard ${ }^{5}$ | Thomas W. Kuyper ${ }^{6}$ | \\ Jacob Heilmann-Clausen ${ }^{7}$ | Irmgard Krisai-Greilhuber ${ }^{8}$ | Claus Bässler,10 | Simon Egli ${ }^{1}$ | \\ Alan C. Gange ${ }^{11}$ | Klaus Høiland ${ }^{3}$ | Paul M. Kirk ${ }^{12}$ | Beatrice Senn-Irlet ${ }^{1}$ | \\ Lynne Boddy $^{13}$ | Ulf Büntgen ${ }^{1,2,14}$ | Håvard Kauserud ${ }^{3}$
}

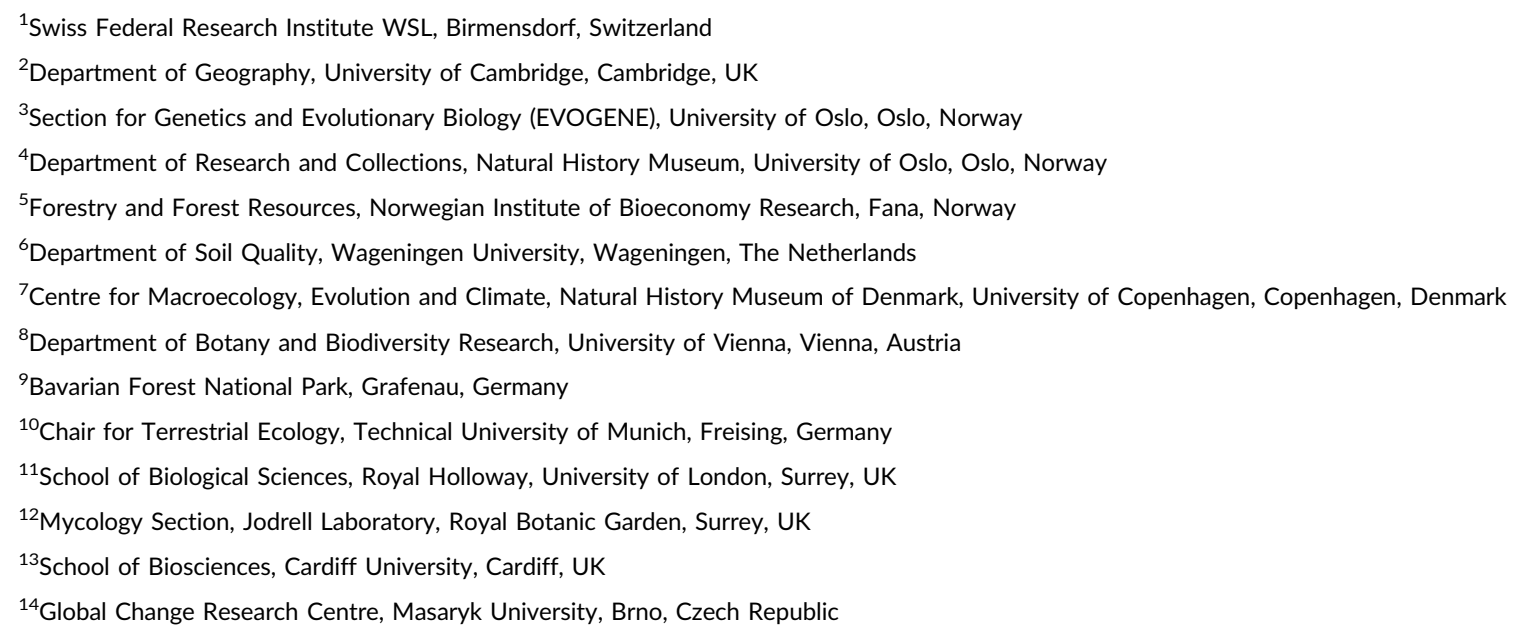

\section{Correspondence}

Carrie Andrew, Swiss Federal Research Institute WSL, Birmensdorf, Switzerland.

Email: carrie.andrew@wsl.ch

\section{Funding information}

The Research Council of Norway; Swiss

National Science Foundation

Michael N. Dawson

\begin{abstract}
Aim: Macroecological scales of species compositional trends are well documented for a variety of plant and animal groups, but remain sparse for fungi, despite their ecological importance in carbon and nutrient cycling. It is, thus, essential to understand the composition of fungal assemblages across broad geographical scales and the underlying drivers. Our overall aim was to describe these patterns for fungi across two nutritional modes (saprotrophic and ectomycorrhizal). Furthermore, we aimed to elucidate the temporal component of fruiting patterns and to relate these to soil carbon and nitrogen deposition.

Location: Central and Northern Europe.

Methods: A total of 4.9 million fungal fruit body observations throughout Europe, collected between 1970 and 2010, were analysed to determine the two main environmental and geographical gradients structuring fungal assemblages for two main nutritional modes, saprotrophic and ectomycorrhizal fungi.

Results: Two main gradients explaining the geography of compositional patterns were identified, for each nutritional mode. Mean annual temperature (and related collinear, seasonal measures) correlated most strongly with the first gradient for both nutritional modes. Soil organic carbon was the highest correlate of the second
\end{abstract}


compositional gradient for ectomycorrhizal fungi, suspected as an indicator of vegetation- and $\mathrm{pH}$-related covariates. In contrast, nitrogen deposition constituted a second gradient for saprotrophic fungi, likely a proxy for anthropogenic pollution. Compositional gradients and environmental conditions correlated similarly when the data were divided into two time intervals of 1970-1990 and 1991-2010. Evidence of compositional temporal change was highest with increasing elevation and latitude.

Main conclusions: Fungal assemblage patterns demonstrate clear biogeographical patterns that relate the nutritional modes to their main environmental correlates of temperature, soil organic carbon and nitrogen deposition. With respect to global change impacts, the highest rates of compositional change by time suggest targeting higher latitudes and elevations for a better understanding of fungal dynamics. We, finally, suggest further examination of the ranges and dispersal abilities of fungi to better assess responses to global change.

\section{KEYWORDS}

assemblage, biogeography, climate, ectomycorrhizal, Europe, fungi, macroecology, saprotrophic, temporal change

\section{1 | INTRODUCTION}

Detecting and understanding broad-scale geographic patterns of organisms are critically important issues in global change research. The patterns of fungal species assemblage distributions have rarely been considered in macroecology, despite the key contributions that fungi make to ecosystem processes (Heilmann-Clausen, Barron, et al. 2014). There are two major functional guilds of fungi that produce macroscopic fruit bodies, based on nutritional mode (i.e. saprotrophic fungi that feed on dead organic matter, and ectomycorrhizal fungi that are mutualistic root symbionts), and each is crucial to ecosystem functioning. It is, thus, important to identify any differences in their geographic patterns and changes in these, especially in relation to global change.

In terms of the known biogeographic patterns of fungi, mycorrhizal fungal species are strongly coupled to their host plants' ranges and climate regions (Tedersoo et al., 2012; Tedersoo, Bahram, Põlme, et al. 2014). Much research has focused on this connection, to the point of extrapolating biotic trends as a means to describe matching, unsurveyed fungal patterns (Bueno et al., 2017; Soudzilovskaia et al., 2015; Swaty, Michael, Deckert, \& Gehring, 2016). Saprotrophic fungi, also, are often considered in terms of their substrates, and their distribution often reflects the availability and quality of specific substrates, for example, wood types and leaf litter (Bässler, Müller, Dziock, \& Brandl, 2010; Heilmann-Clausen, Aude, et al. 2014). Gaps still exist in terms of knowledge of their overall distribution patterns as well as the abiotic processes that likely determine their distributions.

The scattered representations of fungal biogeography studies, to date, have most often extrapolated low but sequence-deep sample intensities (small grain sizes) across large geographical extents, due to the limitations of molecular-based sampling approaches (Unterseher et al., 2011). This "necessary evil" leaves gaps in our knowledge of fungal distributions in space and time. The related fungal community gradients, then, are not continuously represented (due to low density of geographical samples) and, instead, capture categorical levels of what are actually continuous patterns of variation.

The taxonomic coverage across studies can also limit extrapolations. While sequences are identified to operational taxonomic units approximating species (Meiser, Bálint, \& Schmitt, 2014; Taylor et al., 2014), studies have often focused on specific families or genera to benefit phylogenetic knowledge (i.e. Naff, Darcy, \& Schmidt, 2013; Tedersoo, Bahram, Ryberg, et al. 2014). Other studies have focused on higher level taxa of bacteria or fungi (Martiny et al., 2006). Although previous studies have suggested, expectedly, that fungal communities arrange along environmental and geographical gradients, this pattern is yet to be clearly investigated.

In Europe, extensive fungal fruit body records have been catalogued at the largest spatiotemporal scales currently available (Andrew et al., 2017). While the records with comprehensive sampling distributions that span multiple decades make it possible to investigate temporal changes of fungi related to climate, such data sets have so far mainly been used for studying phenology (e.g. Boddy et al., 2014; Büntgen, Kauserud, \& Egli, 2012; Kauserud et al., 2008, 2010, 2012). The uniform coverage of fungal species data throughout a large part of their geographical extent (Andrew et al., 2017), when aggregated at appropriate spatial resolutions and across decades of time, sets this data source apart from molecular-based data. These data capture the entirety of fungal environmental and geographical gradients more completely than current molecular data, 
and in this respect, are ideal sources to better understand environmental correlates to fungal biogeography.

It is the large spatiotemporal range of multisource fungal records collected in varied manners, combined with booming additions through citizen science projects (e.g. Halme, Heilmann-Clausen, Rämä, Kosonen, \& Kunttu, 2012; Heilmann-Clausen, Barron, et al. 2014), that counteracts other limitations of fruit body data. Although the records focus almost exclusively on macrofungi, that is, fungi that form conspicuous fruit bodies, both above- and belowground, these include many of the ecologically most significant groups. For example, habitat preference in wood-decomposing fungi and the decay they cause are well, if not completely, captured with fruit body records (e.g. Heilmann-Clausen et al., 2016). While sporadic and ephemeral fruiting patterns of fungi can limit the accuracy of their representation, the problem is minimized by compiling data across multiple years and at broader spatial resolutions than original point observations (Andrew et al., 2017). Finally, the presence-only data for fruit bodies are the sole source of large-scale historical-tocontemporary records in mycology. Thus, fruit body records offer unique ecological information that may open up new insights into the effects of global change on fungi. Due to the high-spatiotemporal resolution and extent, they serve as a foundation to build upon for biogeographical and macroecological research in mycology.

In this study, we use 4.9 million fruit body occurrences, extracted from a large-scale, European meta-database with more than 6 million fungal fruit body records (Andrew et al., 2017), to identify the major fungal biogeographic compositional patterns in Europe. For fungi in two main nutritional modes, saprotrophic and ectomycorrhizal, we first identified the gradients structuring assemblages and their environmental correlates. We next investigated the differences in fungal compositional patterns between two equal time periods, 1970-1990 and 1991-2010, for each nutritional mode. In particular, we searched for geographical regions with greater compositional change and for the overall environmental drivers that correlated with any compositional shift. As most knowledge in the field is untested, we adopted an inductive, hypothesis-generating approach, that is, not to formulate specific hypotheses beyond a general expectation that the climate and environment (e.g. nitrogen deposition) that structures plant and fungal compositions at smaller scales will likely similarly structure macroscale fungal assemblages. From our results, we generate biogeographical and macroecological hypotheses related to fungi and suggest topics for further research.

\section{2 | MATERIALS AND METHODS}

\section{1 | Fungal data}

This study utilized data from a component of the ClimFun "metadatabase," a set of unified, multisource data which originated from many, independent data repositories of fungal-fruiting records across Europe (Andrew et al., 2017). The data are comprehensive in temporal and spatial coverage, extending decades into the past and covering a large geographic range of Europe. Given the large temporal and spatial coverage of the data, they are a reliable source for answering questions in macroecology. These data have been shown to be especially robust to large-scale phenology analyses (Andrew et al., 2018), demonstrating their potential for biogeographical studies such as here. Earlier bias removal techniques included harmonization of nomenclature, removal of out-of-country records, removal of data with inconsistent or incomplete date records, removal of duplicate records and other techniques standard for formatting these types of data. Due to the large amount of records, these processes did not greatly affect the overall final amounts (e.g. Andrew et al., 2017).

National-scale data in the ClimFun meta-database with a substantial amount of records (i.e. Austria, Denmark, Germany, Netherlands, Norway, Slovenia, Switzerland and the United Kingdom) were selected across a time span from 1970 to 2010, for which data were more reliable due to less recording bias than earlier time periods and also were temporally robust, ensuring stability in climate values (as opposed to interannual weather variability). Species were restricted to the macroscopic fruit body forming Agaricomycotina (the classes Agaricomycetes, Tremellomycetes and Dacrymycetes; including fungi with flattened fruit bodies on wood and soil (corticoid fungi)), as other taxonomic groups comprised very low proportions of the records (Andrew et al., 2017) and, at this spatiotemporal scale, were highly biased in terms of under collection and sampling bias. Taxa were assigned to their dominant nutritional mode based on Rinaldi, Comandini, and Kuyper (2008), Tedersoo and Smith (2013) and with additional species-specific information added through expertize (nutritional mode data compiled 2016 by K. Høiland, University of Oslo, Norway, with additional aid from: B. Senn-Irlet, J. Heilmann-Clausen, A. C. Gange, L. Boddy, S. Egli, T. W. Kuyper, I. Krisai-Greilhuber). The number of records varied between nutritional modes, as did the grid cell representation for each guild (see all results figures to compare between time period amounts and nutritional modes), with greater coverage by saprotrophic fungi.

\subsection{Environmental data}

Available environmental variables were gridded at the $50 \times 50 \mathrm{~km}$ level after connecting the ClimFun records data in earlier steps to open-source metadata at their highest available resolutions (i.e. geographical points), thus gaining the most precision possible in terms of fruiting records and their associated environment. Environmental data were obtained and formatted from each of the following opendata sources; climate and elevation data were extracted at the 2.5 and $0.5 \mathrm{~min}$ resolution, respectively (equivalent to approximately 4.5 and $1 \mathrm{~km}$ at the equator), from WorldClim (http://www.worldclim. org; Hijmans, Cameron, Parra, Jones, \& Jarvis, 2005). GIMMS AVHRR Global NDVI-3g (normalized difference vegetation index) data with 1/12-degree resolution (approximately $9.5 \mathrm{~km}$ at the equator) were extracted from Ecocast (https://ecocast.arc.nasa.gov). The average of annual averages of monthly mean value concatenated climate data composites for the period 1982-2010 was used. NDVI corresponds to the start of spring in northern latitudes and is thus 
often used as a measure of initial primary productivity (Nielsen et al., 2012; Pettorelli et al., 2005). Percentage soil organic carbon was extracted from the OCTOP (Topsoil Organic Carbon Content for Europe) data set, from the Joint Research Centre-European Soil Data Centre (ESDAC), with 1-km original resolution (http://esdac. jrc.ec.europa.eu/content/octop-topsoil-organic-carbon-content-eur ope). Reduced and oxidized nitrogen deposition data were obtained from Greenhouse Gas Management in European land use systems (GHG Europe) FP7, using $0.25^{\circ}$ (approximately $27-28 \mathrm{~km}$ at the equator) NCAR CTM data (http://www.europe-fluxdata.eu/ghg-eur ope/data/others-data). Finally, land cover was extracted from the European Environment Agency (EEA) Corine Land Cover (CLC) 2006 raster data (version 17) with an original $100 \mathrm{~m}$ resolution (http:// www.eea.europa.eu/data-and-maps/data/corine-land-cover-2006-ra ster-3). While data with varying spatial resolutions are not ideal, this issue was balanced against utilizing data with the best temporal resolution matching the fungal recordings as well as the ability to find and extract data for each covariate.

To minimize multicollinearity, pairwise Pearson correlation coefficients between all potential environmental covariates were calculated (Appendix S1) and variables with a coefficient below a threshold of 0.60 (absolute value) were retained (cf. Dormann et al., 2013). Total and seasonal precipitation were positively correlated, as were the annual, seasonal and ranges in temperature. In the case of temperature, the latter two were positively correlated with easting (longitude) and were thus not retained. Nitrogen deposition (both $\mathrm{NH}_{x}$, and $\mathrm{NO}_{y}$ ) was correlated with northing (negative) and easting (positive). $\mathrm{NH}_{\mathrm{x}}$ was selected for further analyses, serving also as a proxy for $\mathrm{NO}_{y}$, with which it was strongly correlated. NDVI was correlated with northing and easting but was retained as it is a more direct measure of seasonal primary productivity than northing or easting. Thus, nine variables were used in the analyses (Appendix S1; Figure 1): six environmental variables (mean annual temperature, summed annual precipitation, $\mathrm{NH}_{\mathrm{x}}$, soil percentage organic carbon, NDVI and dominating land cover class) and three geographical variables (northing, easting and elevation). While these selected variables vary along gradients on the broad scales that are addressed in our study, it should be noted that correlative relationships do not imply causal relationships.

\section{3 | Data preparation}

Fungal species records per latitude-longitude coordinate were summed within each $50 \times 50 \mathrm{~km}$ grid extending over Europe and matched to UTM (Universal Transverse Mercator coordinate system; a more geographically accurate projection for both northing and easting bounds) zone 32. Environmental data were extracted for each fungal record (to precise latitude-longitude positions) and were then averaged within each grid cell to match the gridded fungal data. Land cover was recorded as the CLC class with the highest number of fungal records in each grid cell. Values for each environmental variable were originally linked directly to each species record the most precise spatial resolution possible; thus, the values reported for grid cells are means for all data points found within each cell and not an overall equal-area average across each grid cell. They are optimally predictive of environmental conditions leading to a fruit body presence. Data were originally analysed at three spatial resolutions $(50 \times 50 \mathrm{~km}, \quad 20 \times 20 \mathrm{~km}$ and $10 \times 10 \mathrm{~km})$, with the $50 \times 50 \mathrm{~km}$ resolution the one that best captured large-scale compositional dynamics while being least subject to spatial bias (Araújo, Thuiller, Williams, \& Reginster, 2005). Geographical variables were represented by the value of the grid cell centre point.

To understand temporal effects on compositional dynamics, for all taxa combined as well as saprotrophic and ectomycorrhizal taxa separately, the fungal data were analysed for the whole time span (1970-2010) as well as for two time periods (split equally into 1970-1990 and 1991-2010). To help reduce collector biases in species representation, grid cells (grids) with less than a total of 499 records, summed across all fungal species, were removed from the whole time period data set. Grids cells with less than a total of 249 records, summed across all fungal species in the earlier time period, were removed, as were those lacking records across both time periods. The impact of the value chosen for the minimum amount of records within grid cells (249) was analysed during model optimization. Similar model results, or less optimal models, were obtained with the number of records per grid cells of less than 4999, 2499, 999 and 249 summed records per grid (half these values for the two time periods). The influence of rare species was clear in grids when those with only less than two summed records were removed (and inappropriate for analysis). The influence of abundantly fruiting species was minimized by collapsing records to single units per geographical location (i.e. record duplications were removed), though our data are populated by rarer to abundantly fruiting taxa; hence, the need for studies across fungal tissue and methodological types.

\subsection{Statistical analyses}

To summarize the main gradient structure of fungal assemblage compositions, global nonmetric multidimensional scaling (GNMDS) and detrended correspondence analysis (DCA) ordinations were obtained in accordance with the multiple parallel ordination approach of van Son and Halvorsen (2014, and references therein), using the vegan (Oksanen et al., 2013) and MASS (Venables \& Ripley, 2002) packages in R. By this procedure, only ordination axes that are extracted by both methods were accepted as important compositional gradients, thereby ensuring that spurious axes (which may occasionally be produced by any ordination method; Økland, 1996) were not subjected to further interpretation. Many combinations of data properties, settings and options for the methods were explored in the initial phase of the data analyses, including counts, relative counts and frequencies as measures of species' abundances in the grid cells; combined with the whole as well as the two time period data sets as well as for all saprotrophic and ectomycorrhizal subsets of fungal communities. GNMDS analyses with count data utilized the BrayCurtis dissimilarity index while the Jaccard index was used for frequency data. Each of the following settings was applied to the count 
(a)

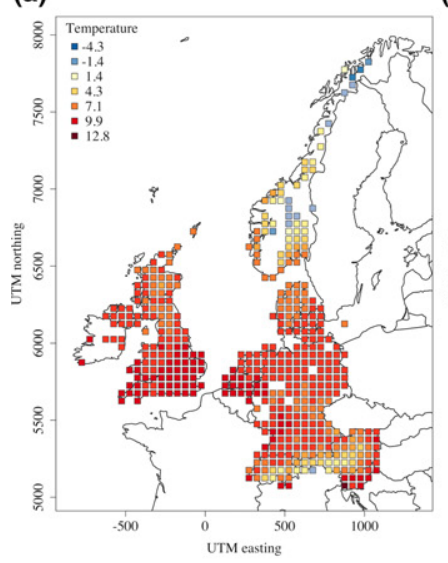

(e)

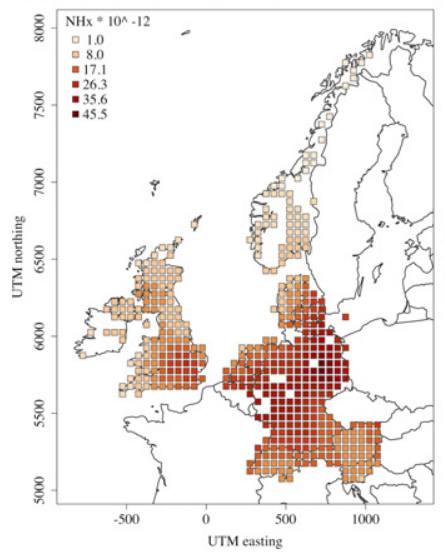

(b)

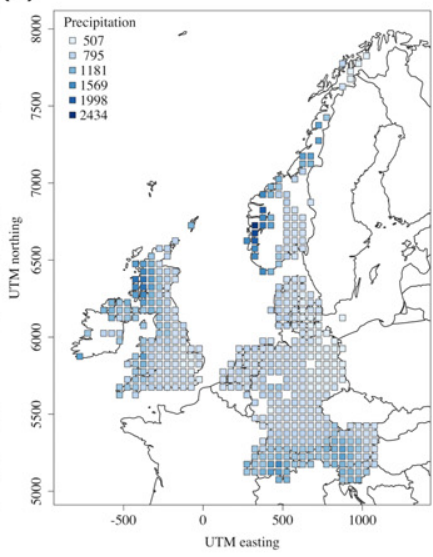

(f)

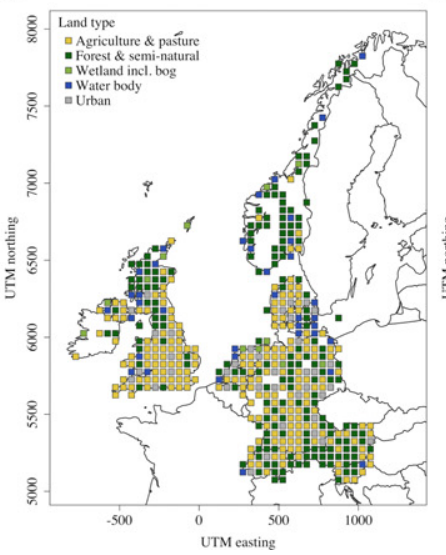

(c)

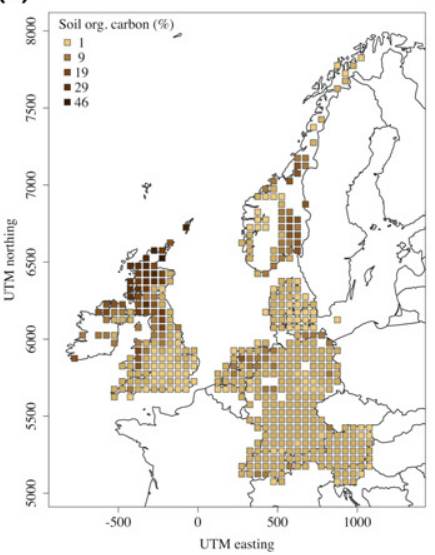

(g)

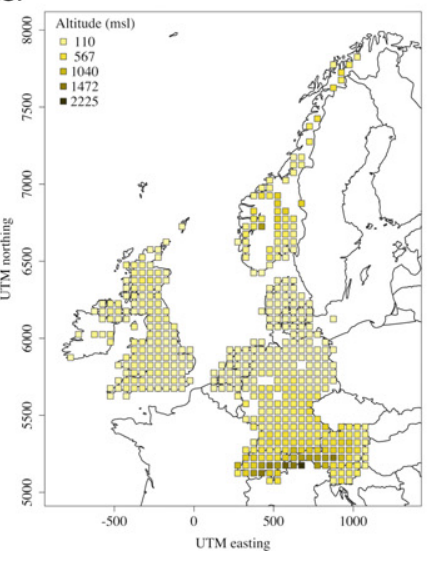

(d)

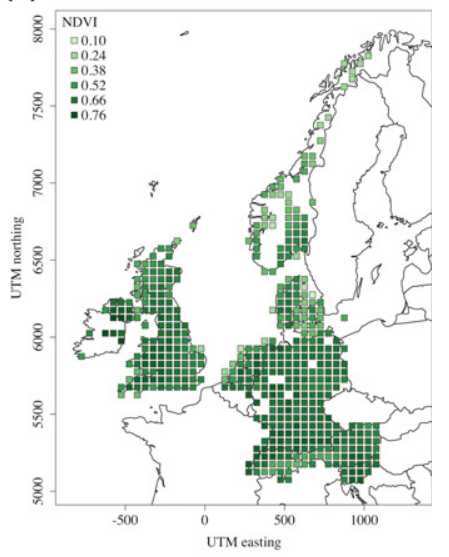

FIGURE 1 Environmental covariate gridded maps displaying mean values, by geocoordinates linked to amount of fruit body records, for (a) mean annual temperature (degrees C), (b) averaged total precipitation per year (mm), (c) mean percent soil organic carbon, (d) mean NDVI, where lower values are less productive, (e) mean ammonia(-um) levels, $\mathrm{NHx}\left(\mathrm{kg} \mathrm{N} \mathrm{m}^{-2} \mathrm{~s}^{-1} \times 10^{-12}\right.$ ), (f) land cover class (CLC 1), and (g) mean elevation (msl) [Colour figure can be viewed at wileyonlinelibrary.com]

data, and the first three to relative count and frequency data, during GNMDS analyses: no transformations or standardizations (absolute values were used), geodesic transformation, Hellinger standardization, power transformation and Wisconsin double standardization. For further interpretation, DCA with power function transformed count data was selected. The axes of these DCA's were confirmed by GNMDS by calculating pairwise correlation coefficients between the axes. Between the models, axis 1 correlations ranged from 0.74 to 0.93 while axis 2 ranged from 0.23 to 0.82 , with lowest correlation between ectomycorrhizal and saprotrophic groups.

Ordination results were visualized by plotting DCA axis scores on the positions of each grid cell. The difference between ordination scores for each of the two axes and for the two time periods was used as the response variable in an analysis of temporal change patterns. Kendall's nonparametric correlation coefficient $\tau$ was used to assess the significance of environmental components in explaining community variability as represented by the DCA axes (Table S2). Variables that strongly correlated with one or both of the first two DCA axes were fitted to the ordination diagram using linear regression and displayed as either linear-termed fixed effects or cubic smooth splines (Liu et al., 2008; Mahecha, Martínez, Lischeid, \&
Beck, 2007; Økland, 1996; Tenenbaum, De Silva, \& Langford, 2000; Wood, 2006). The categorical land cover variable was analysed with the function envfit in vegan and was found always to be significant (data not shown). The function also verified significance of the Kendall's tau correlations for all other variables. Absolute values of $\tau>0.30$ were considered substantially correlated with a DCA axis while $\tau$ values in the interval $0.20-0.30$ were considered as marginal.

The statistical significance of the temporal difference in fungal species composition (originating from one DCA) was assessed by three methods: paired $t$ tests of the individual DCA axes scores; a multivariate paired Hotelling's $T$-squared test for the axes differences with respect to time period and a principal component analysis (PCA) on the matrix of compositional change. Further PCA analyses with proportions rejected a concern that compositional change was due to sampling bias between the two time periods. As results were all complementary, DCA score differences were selected to be plotted geographically as a demonstration of compositional change between the time intervals.

While not emphasized, as our goals concerned determining how the biogeography of fungal assemblages related to environmental gradients, we determined the potential that any temporal changes in 
fungal assemblages were mostly the result of specific species' changes by time (see supplemental material). Indicator species analyses were conducted on the results of the DCA scores for each of the two time intervals, utilizing the difference in scores between the first and second time periods for the response matrix. The species were divided into groups by positive, negative or relatively little (no; between -0.1275 and 0.1275 for saprotrophic and -0.0625 and 0.0625 for ectomycorrhizal groups) DCA axis score change between the time periods. The groups were created by separating scores into equal components of DCA score matching the colour coding for figures created. Analysis was conducted with the indicspecies package. All data formatting and analyses were implemented in $\mathrm{R}$ version 3.2.2.

\section{3 | RESULTS}

The primary gradients of saprotrophic and ectomycorrhizal fungal species assemblages were both correlated with mean annual temperature (Figures 2a and 3a; Appendix S2); Kendall's $\tau$ values were -0.55 for saprotrophic and -0.48 for ectomycorrhizal fungi. The highest correlations for each group were for temperatures linked to cold-season measures (coldest month or coldest quarter). Grid cells at the geographical and temperature extremes (the Norwegian and Alp mountain ranges) were similar with high DCA axis 1 scores, most clearly seen for the saprotrophic fungi. In contrast, grid cells from western, coastal and low-lying parts of Europe occurred along the opposite, low-score DCA axis 1 gradient.

The second compositional gradient (DCA axis 2) differed between nutritional modes. For saprotrophic assemblages, the gradient reflected patterns related to nitrogen deposition levels ( $\tau=-0.49$; Figure 2b). DCA axis 2 scores increased from central Europe to coastal areas of the UK and Norway, which matched general nitrogen patterns (Figure 1e). In contrast, the second assemblage gradient for ectomycorrhizal fungi separated assemblages of grid cells from Northern to Central Europe (Figure 3b) and was correlated with soil organic carbon content $(\tau=0.36)$ (Figure 1c). The entire fungal community reflected similar patterns to the saprotrophic fungi (Appendices S2 and S3) and is thus not discussed further.

When separated into two time periods (1970-1990 and 19912010), patterns reflected those described for the whole time period. Temperature was again the main correlate along the primary gradient identified for saprotrophic $(\tau=-0.51)$ and ectomycorrhizal ( $\tau=-0.38$ ) fungal assemblages (Figure 4), with cold-season temperatures also showing high correlations (Appendix S2). Patterns reflected those described for the whole time period. As with the whole time period, saprotrophic fungal assemblages were separated along a second gradient related to $\mathrm{NHx}(\tau=-0.37)$, and ectomycorrhizal fungal assemblages along a gradient related to soil organic carbon $(\tau=0.37)$ and mean annual temperature $(\tau=-0.43)$.

The saprotrophic fungal assemblage gradients correlated with temperature (axis 1) and nitrogen (axis 2). For both of the gradients, the greatest DCA score change was for grid cells situated to the north and at higher elevations, that is, in the Norwegian mountain region (Figure $4 \mathrm{a}, \mathrm{b}$ ). For the first, temperature-related gradient, a pattern of change was found in the opposite direction in at least some regions of the Alps mountain range of Switzerland and Austria. There were no robust indicator species for any of the DCA axis change groups in terms of specificity (probability of a group based on a species' presence) and fidelity (probability of finding a species in a group), though many species matched high-specificity values (Appendix S4). Nitrogen was similarly strongly correlated with DCA scores along the second gradient (Appendix S2), with areas of lower nitrogen amounts tending to occupy either extreme along the gradient. Areas in Central and Western Europe exhibited the least amount of temporal change along both gradients. Although the number of grid cells was fewer for ectomycorrhizal fungi, there was a similar trend of greatest temporal differences in assemblages at the highest latitudes and elevations (Figure 4c, d). No highly matched indicator species were found for any group, though as with the saprotrophic fungi, many species contained high-specificity values but very low-fidelity values (Appendix S5).

\section{DISCUSSION}

Assemblage gradients for both saprotrophic and ectomycorrhizal fungi correlated with mean annual temperature (and collinear, coldseason temperature measures), which, as expected, were patterned by geography and elevation. Assemblages with higher mean annual temperatures were more similar to each other than to those at lower temperatures (Figures 2 and 3a, c, e). Most notably, the composition of fungal assemblages in mountainous regions was similar, regardless of whether they were situated in Norway or the Alps region of Switzerland and Austria. If we were able to conduct the same analyses at a more precise spatial scale that could incorporate vegetation data into the models, we expect that, in line with earlier studies, we would find a significant relationship between the fungal and environmental gradients, as identified with respect to fungal composition gradients, with vegetation type (e.g. Bueno et al., 2017; Soudzilovskaia et al., 2015; Swaty et al., 2016; Tedersoo et al., 2012). A clear next challenge is to connect the fungal-environment relationships to the fungal-vegetation relationships, ideally while simultaneously separating direct and indirect effects from each other.

The second main assemblage gradient (DCA axis 2) was both different in its pattern and varied in the main environmental correlate between the nutritional modes, though it was relatively uniform in terms of geographic and altitudinal distribution (Figures 2 and $3 b, d$, e). The saprotrophs displayed assemblage patterns related to a gradient of $\mathrm{N}$ deposition, which itself reflected oceanicity-continentality patterning, and which is a likely proxy for anthropogenic impacts on the environment. The ectomycorrhizal pattern related to soil organic carbon and was less geographically structured, though similar to that found by Gange et al. (2017) in the UK. While our results cannot determine causation, different feeding strategies may explain the correlation of nitrogen with saprotrophic fungal assemblages and soil 
(a)

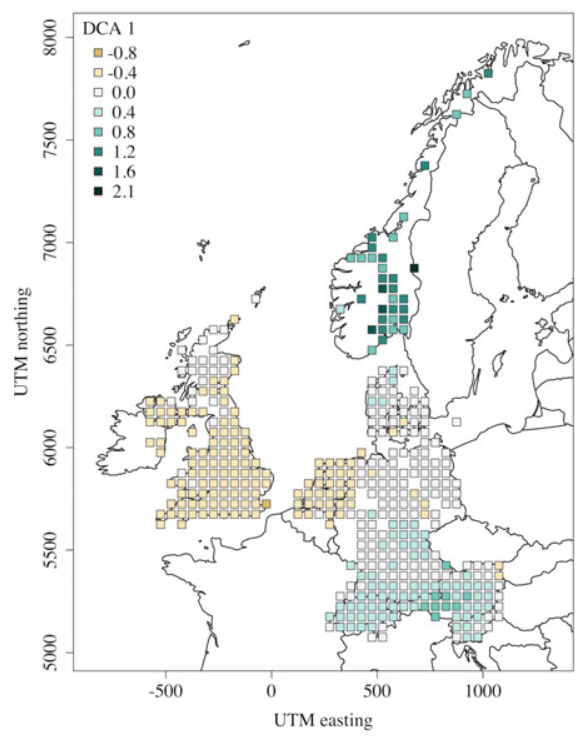

(b)

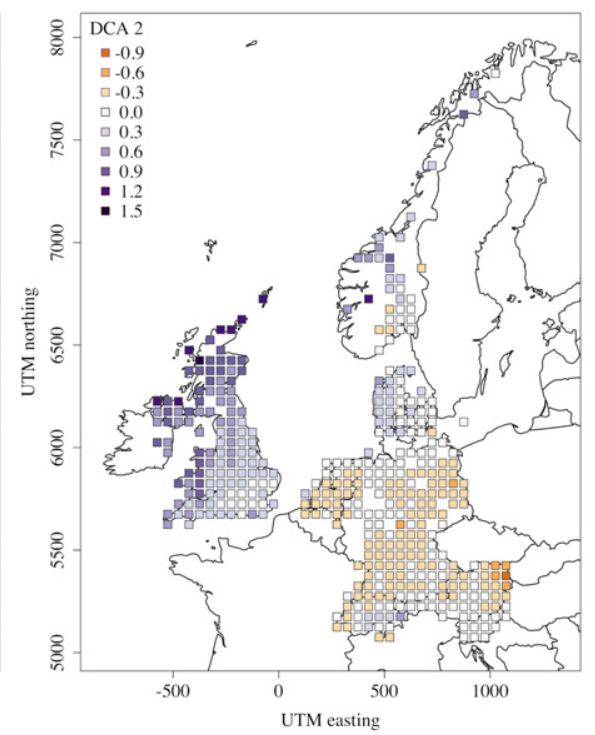

(c)
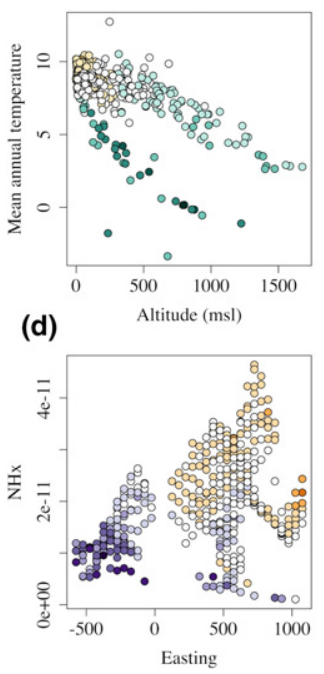

(e)

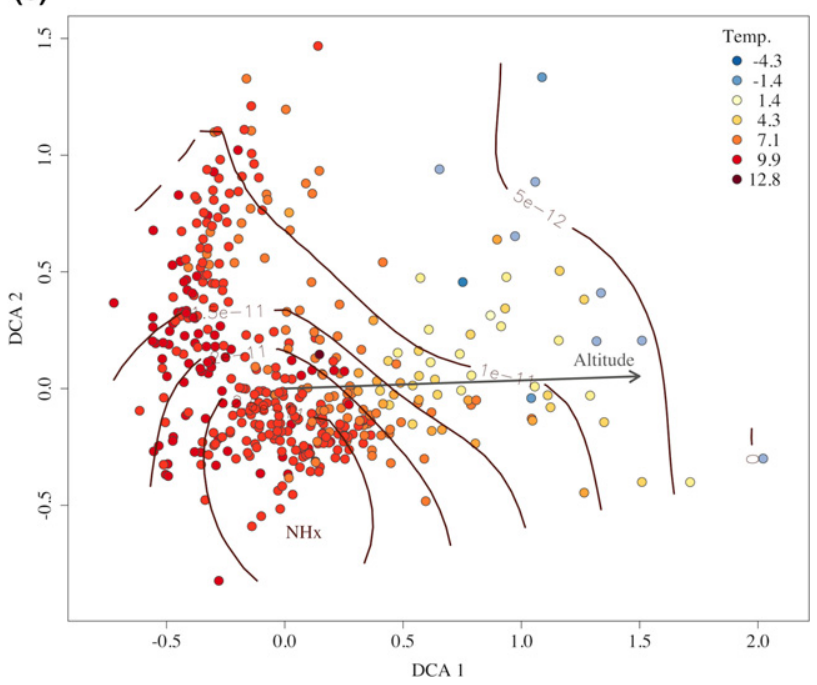

FIGURE 2 Gradients in the composition of saprotrophic fungal communities, their biogeographical distributions and environmental correlates. Compositional similarities are represented by DCA axis 1 (a, c) and axis 2 (b, d) gradients mapped onto $50 \times 50 \mathrm{~km}$ grids. Shading reflects DCA axis gradients, centred at zero (white), with darker values at either extreme. DCA plots (e) demonstrate the influence of mean annual temperature, elevation and nitrogen $(\mathrm{NHx})$, all of which were highly correlated with either of the DCA axes [Colour figure can be viewed at wileyonlinelibrary.com]

organic carbon (SOC) with ectomycorrhizal fungal assemblages (Appendix S2).

Ectomycorrhizal fungal roles in carbon sequestration and cycling are increasingly recognized, especially in northern latitude forests (Averill \& Hawkes, 2016; Clemmensen et al., 2013; Kyaschenko, Clemmensen, Karltun, \& Lindahl, 2017). The high correlation we found between an assemblage composition gradient (the 2nd DCA axis) and SOC content suggests that ectomycorrhizal fungi not only respond to but also causally contribute to processes of organic matter accumulation and, hence, carbon sequestration (Figure 1c, f). We effectively captured the distributional gradation of basidiomycete taxa by vegetation type from acidic, carbon-rich northern bogs and fens of the UK, transitioning to ectomycorrhizal dominance in northern and mountainous forests of Scandinavia and the Alps region of
Switzerland and Austria, on predominantly mor soils. Those locations can be contrasted with the more continental pasturelands and woodlands containing either less woody plants or forests with different ectomycorrhizal fungal communities and soil types. Soil $\mathrm{pH}$, which is often highly correlated with turnover in fungal community composition (Rineau \& Garbaye, 2009) and implicated in fungal biogeography (Tedersoo, Bahram, Põlme, et al. 2014), is strongly, negatively correlated with SOC content at a European scale (Bueno et al., 2017). $\mathrm{SOC}$ can also be considered as an inverse proxy of $\mathrm{pH}$. This second main compositional gradient signifies the importance of carbon and structurally bound compounds (and nonmeasured determinants of soil carbon, for example, vegetation and soil $\mathrm{pH}$ ) as well as any consequential potential changes (related to climate or land use change) to fungi and their ecosystem services. 
(a)

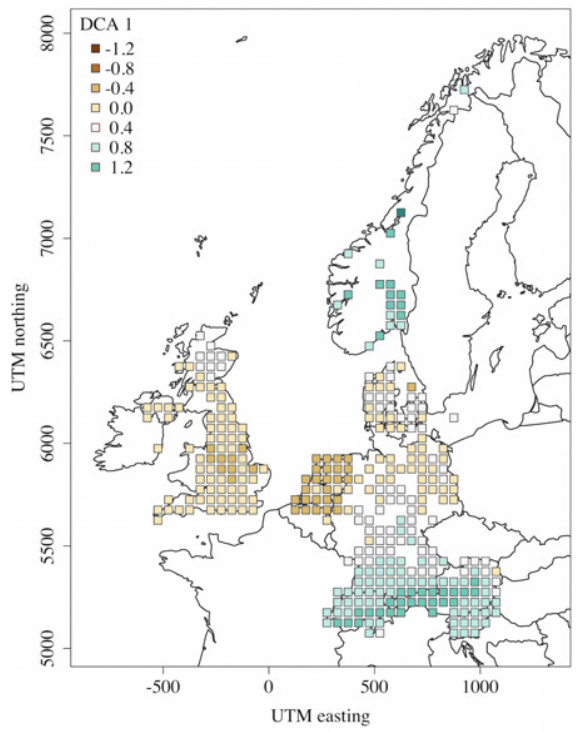

(b)

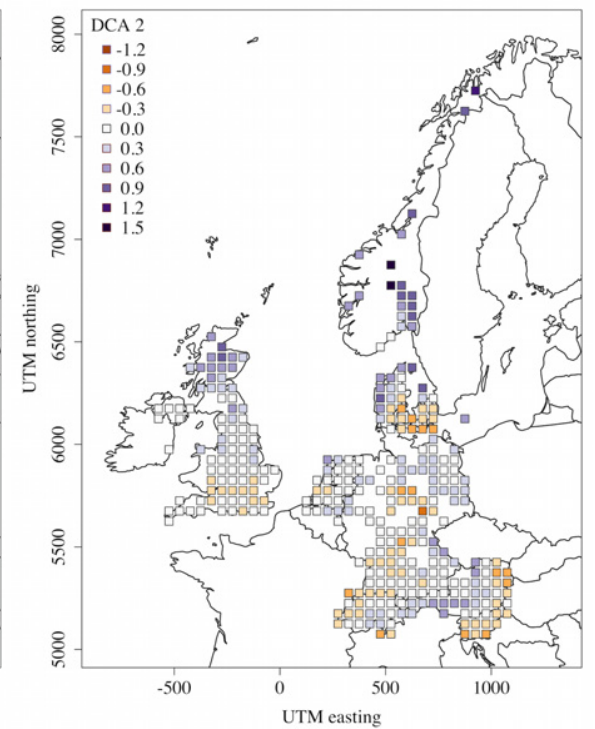

FIGURE 3 Gradients in the composition of ectomycorrhizal fungal communities, their biogeographical distributions and environmental correlates. Compositional similarities are represented by DCA axis $1(a, c)$ and axis 2 (b, d) gradients mapped onto $50 \times 50 \mathrm{~km}$ grids. Shading reflects DCA axis gradients, centred at zero (white), with darker values at either extreme. DCA plots (e) demonstrate the influence of mean annual temperature, elevation and percent soil organic carbon, all of which were highly correlated with either of the DCA axes [Colour figure can be viewed at wileyonlinelibrary.com] (c)

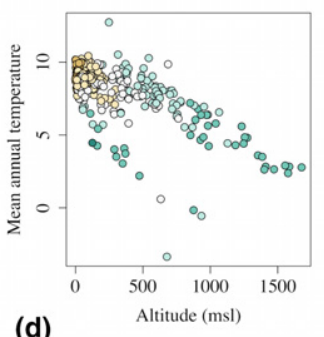

(d)

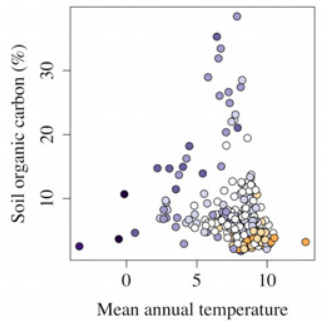

(e)

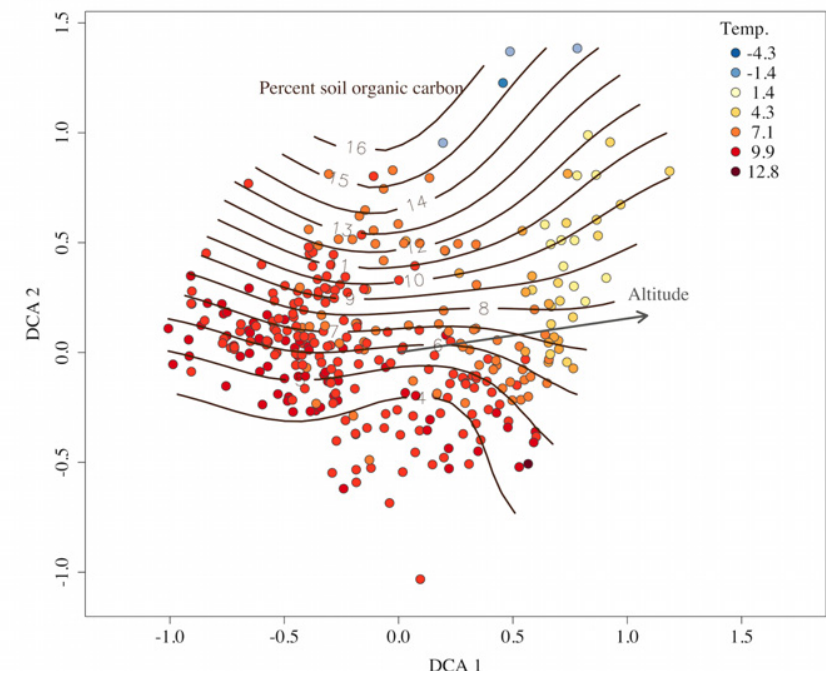

Neither of the two most important ectomycorrhizal compositional gradients were strongly correlated with nitrogen deposition amounts (a correlation of $\tau=-0.23$ was found for the second DCA axis; Appendix S2), which might at a first glance be surprising because effects of $\mathrm{N}$ deposition on ectomycorrhizal fungal communities have been well established (Arnolds, 1991; Avis, McLaughlin, Dentinger, \& Reich, 2003; Lilleskov, Fahey, \& Lovett, 2001; Peter, Ayer, \& Egli, 2001). We suggest two main explanations for this discrepancy of our results with those of others: First, a weaker correlation means that the assemblage gradients were structured more strongly by other factors, that is, temperature and soil carbon, rather than nitrogen deposition per se. Accordingly, our results are compatible with a considerable effect of nitrogen deposition on fungi but suggest interactions with carbon sequestration that have also been shown experimentally (De Vries et al., 2009). Alternatively, the second time span (1991-2010) might have reduced visible $\mathrm{N}$ impacts on assemblages, as nitrogen pollution especially started to abate from 1994 onwards (van Strien, Boomsluiter, Noordeloos, Verweij, \&
Kuyper, 2017). This is in accord with the reduction of $\mathrm{N}$ that has recently taken place in the Netherlands, which has caused a marked rebound by once-affected ectomycorrhizal taxa, especially those considered nitrogen-sensitive (nitrophobic) (van Strien et al., 2017). A manipulative experiment testing the abatement of longer term nitrogen addition similarly demonstrated a reconvergence to greater community similarity with nonnitrogen enriched treatments than those with persistent nitrogen addition (Andrew C. and Avis P., unpublished data). Temporally dynamic environmental variables, when available, would be of further assistance in clarifying responses, as would careful inspection between regions.

Interestingly, while saprotrophic fungi typically are less documented and, thus, generally thought to exhibit less sensitivity to nitrogen deposition, the second compositional gradient was highly correlated with nitrogen deposition (Figure $2 b, d, e)$. Studies of nitrogen addition effects on saprotrophs have, however, pinpointed wood decay fungi as being susceptible (Allison, Hanson, \& Treseder, 2007). Community impacts of elevated nitrogen level have also previously 
(a)

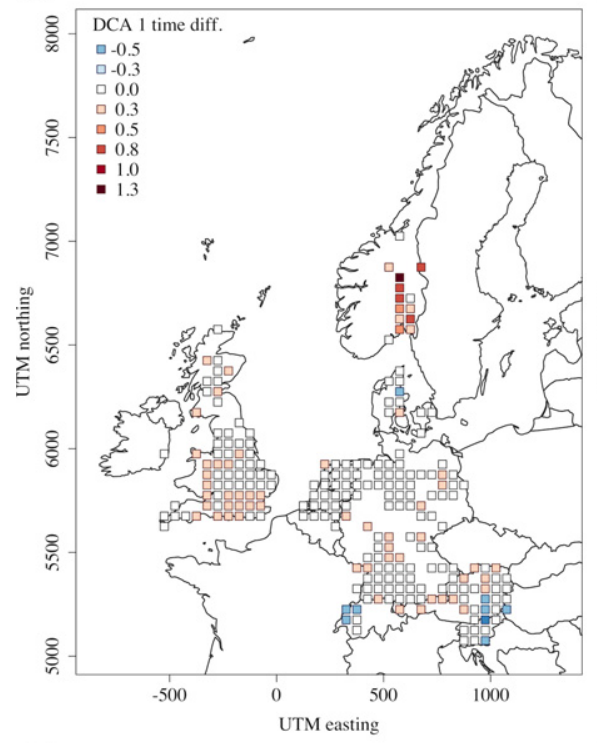

(c)

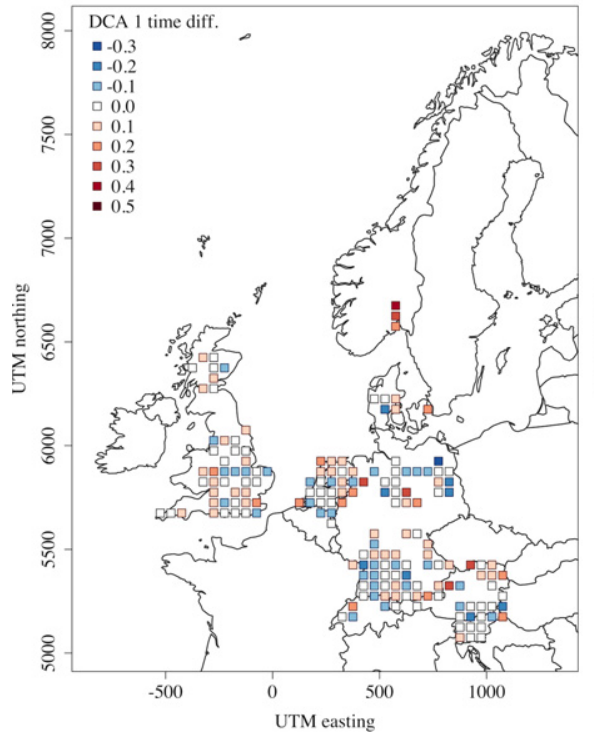

(b)

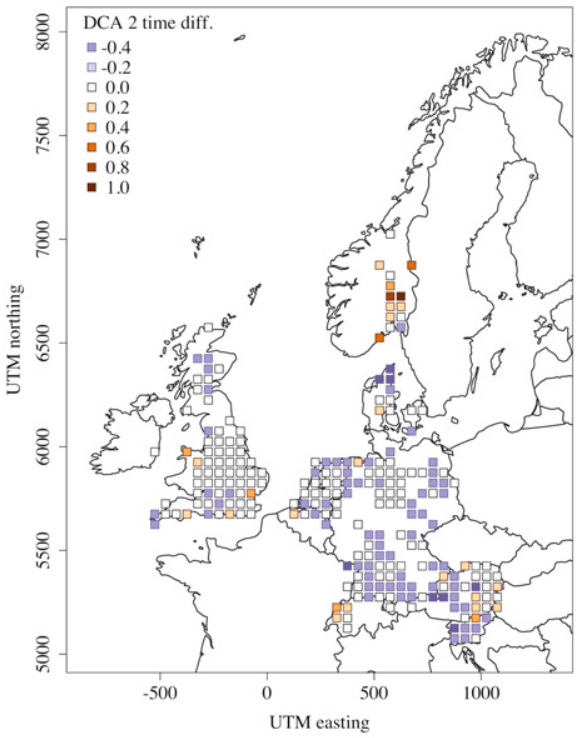

(d)

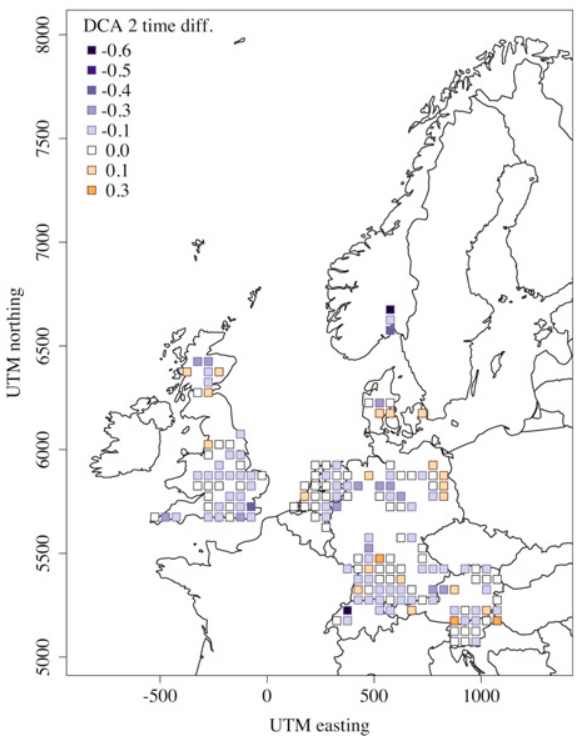

FIGURE 4 Saprotrophic (a, b) and ectomycorrhizal (c, d) fungal community differences between two time periods (1970-1990 vs. 1991-2010). The temporal differences of communities by the two main DCA gradients $\left(t_{2}-t_{1}\right)$ are shown mapped. All point shadings are centred at zero (coloured white), with shading reflecting DCA axis gradients of darker values at either extreme [Colour figure can be viewed at wileyonlinelibrary.com] been found (Allison et al., 2009), though muted compared to our own results. The molecular-based approach by those authors, covering a broader taxonomic range (at a far smaller spatial scale), include many more taxa of the Ascomycota which, compared to macrofungi, are likely to be less susceptible to $\mathrm{N}$. Thus, the focus on Basidiomycota and the inclusion of wood-decaying fungi in our macrofungal data set may explain the more pronounced community response to large-scale $\mathrm{N}$ content (Figure 1e). Nitrogen was also significantly correlated with community structure when analysed across the two time intervals (Appendix S2). Our results suggest that saprotrophic macrofungi are an important group to focus on in terms of nitrogen effects, with certain groups more sensitive than even ectomycorrhizal fungi. The marginal correlation with precipitation $(\tau=0.27)$ should be further explored, as it likely represents a community gradient that reflects a response to oceanic versus continental climates.

Fungal assemblage composition varied with time, but only in certain regions and with a magnitude that varied in relation to the environmental covariates (Figure 4). The more dramatic temperature range shift by elevation (compared to latitude), and consequent assemblage change, appears to match the distributional patterns of plant species ranges (Halbritter, Alexander, Edwards, \& Billeter, 2013) and mirrors bioclimatic zonation related to temperature (annual temperature, length of growing season). Our results indicate that fungal assemblages in European mountain ranges are more similar, across large geographic distances, than with those of the lowlands. This may be due to similarities in land cover type (Figure 1f), hosts or climatic factors themselves. Elevation-structured communities differently by latitude, for both saprotrophic and ectomycorrhizal fungi, supporting the suggestion that the indirect effects of latitude and elevation cannot be assumed similar even if both are structured by temperature (Grytnes et al., 2014; Halbritter et al., 2013), which also directly affects organisms. Other factors can contribute independently to differences between each mountain range, for example, slope steepness, precipitation (Engler et al., 2011) and components 
of biotic interactions (Pellissier et al., 2013) and could explain some of the discrepancies in assemblage gradient changes. Relating dispersal to range shifts would also help clarify responses (Siefert, Lesser, \& Fridley, 2015).

Greater change in assemblages occurred with saprotrophic than ectomycorrhizal fungi, evidenced by a wider range in the difference of DCA axes scores between time periods (Figure 4). More marked temporal-based changes in phenological responses by saprotrophic fungi have also consistently been found, suggesting that these fungi may respond more rapidly than ectomycorrhizal fungi, and in a variety of ways, that is, by compositional as well as phenological changes (Andrew et al., 2018; Kauserud et al., 2012). It would be of ecological interest to quantify the extent to which the latter is a direct cause of the former. The degree to which greater saprotrophic temporal change is related to management practices, forest stand succession or other global change components also requires further study (Bässler et al., 2010; Heilmann-Clausen, Aude, et al., 2014; Nordén, Penttilä, Siitonen, Tomppo, \& Ovaskainen, 2013). The effects of management might require, however, a more precise scale resolution than that used in the current, broad-scale study.

Our results may serve as a platform for further macroecological research on fungi. For example, the abiotic and biotic components of the most clearly defining biogeographical gradients should be further examined, especially in relation to global change. We suggest priority be given to biogeographical relationships of variables that act upon fungi in a direct way, that is, temperature and moisture, given how they nonadditively structured fungal assemblages, especially in terms of latitude and elevation. As mentioned earlier, it is imperative to better connect fungi, plants and the environment, as science currently relies too often on two-way relationships rather than a network approach capable of addressing all three main components. Similarly, we must understand how fungal ranges, at large scales, are distributed relative to one another as well as with respect to their hosts and/or substrates. Finally, as we report on macrofungal fruit bodies (as a proxy for understanding fungal assemblage patterns overall), a primary role of which are related to reproduction and dispersal of fungi, we suggest that adding in information on long-distance dispersal abilities - be it via spores, vegetative structures, host or animal vectors - will help clarify the potential for movement of fungi into new and changing habitats. These suggestions all lead to consideration of the potential for further change of fungal communities under future global change scenarios, and what the ecological relevance might then be.

\section{ACKNOWLEDGEMENTS}

Two sources are acknowledged for financial support: The Research Council of Norway, project "Climate change impacts on the fungal ecosystem component (ClimFun)" (11 of 38 months), and the Swiss National Science Foundation, project "Linking European Fungal Ecology with Climate Variability" (11 months). We thank Drs. Dag Endresen, Vegar Bakkestuen and Anders Nielsen for open-source data acquisition. As always, our appreciation to employees and volunteers that over the years collected, managed and provided rights to the fungal data: the Austrian Mycological Society and Wolfgang Dämon; the Swiss national database (www.swissfungi.ch) and Peter Jakob; Deutsche Gesellschaft für Mykologie (German Mycological Society) and Dr. Martin Schmidt; the Danish Fungal Atlas project and Tobias Frøslev, Thomas Læssøe, Jens. H. Petersen and Jan Vesterholt; the Netherlands Mycological Society (NMV) and A. van den Berg; the Mycological Herbarium at the Natural History Museum (University of Oslo); the Slovenian Forestry Institute, the Central database of fungi in Slovenia, the Slovenian Mycological Association and Dr. Nikica Ogris; www.fieldmycology.net for support sources of the UK national database. We also acknowledge critical and constructive comments of the editor and three anonymous reviewers.

\section{DATA AVAILABILITY}

The fungal and associated metadata are provided as used for analyses in this study, gridded at the $50 \times 50 \mathrm{~km}$ resolution, as the whole time period or two time periods and as saprotrophic taxa or ectomycorrhizal taxa. Additionally, gridded fungal data have been provided at the $10 \times 10 \mathrm{~km}$ resolution, also as either the whole time period or two time periods, and as saprotrophic or ectomycorrhizal taxa. Please see the included information on original sources of data or else the methods and acknowledgments sections of this manuscript.

\section{ORCID}

Carrie Andrew iD http://orcid.org/0000-0002-0524-8334

\section{REFERENCES}

Allison, S. D., Hanson, C. A., \& Treseder, K. K. (2007). Nitrogen fertilization reduces diversity and alters community structure of active fungi in boreal ecosystems. Soil Biology and Biochemistry, 39, 1878-1887. https://doi.org/10.1016/j.soilbio.2007.02.001

Allison, S. D., LeBauer, D. S., Ofrecio, M. R., Reyes, R., Ta, A. M., \& Tran, T. M. (2009). Low levels of nitrogen addition stimulate decomposition by boreal forest fungi. Soil Biology and Biochemistry, 41, 293-302. https://doi.org/10.1016/j.soilbio.2008.10.032

Andrew, C., Heegaard, C., Gange, A. C., Senn-Irlet, B., Egli, S., Kirk, , ... Boddy, L. (2018). Congruency in fungal phenology patterns across dataset sources and scales. Fungal Ecology, 32, 9-17. https://doi.org/ 10.1016/j.funeco.2017.11.009

Andrew, C., Heegaard, E., Kirk, P. M., Bässler, C., Heilmann-Clausen, J., Krisai-Greilhuber, I., ... Kauserud, H. (2017). Big data integration: Pan-European fungal species observations assembly that addresses contemporary questions in ecology and global change biology. Fungal Biology Reviews, 31, 88-98. https://doi.org/10.1016/j.fbr.2017.01. 001

Araújo, M. B., Thuiller, W., Williams, P. H., \& Reginster, I. (2005). Downscaling European species atlas distributions to a finer resolution: Implications for conservation planning. Global Ecology and Biogeography, 14, 17-30. https://doi.org/10.1111/j.1466-822X.2004.00128.x

Arnolds, E. E. F. (1991). Decline of ectomycorrhizal fungi in Europe. Agriculture, Ecosystems \& Environment, 35, 209-244. https://doi.org/10. 1016/0167-8809(91)90052-Y 
Averill, C., \& Hawkes, C. V. (2016). Ectomycorrhizal fungi slow soil carbon cycling. Ecology Letters, 19, 937-947. https://doi.org/10.1111/ ele.12631

Avis, P. G., McLaughlin, D. J., Dentinger, B. C., \& Reich, P. B. (2003). Long-term increase in nitrogen supply alters above-and below-ground ectomycorrhizal communities and increases the dominance of Russula spp. in a temperate oak savanna. New Phytologist, 160, 239-253. https://doi.org/10.1046/j.1469-8137.2003.00865.x

Bässler, C., Müller, J., Dziock, F., \& Brandl, R. (2010). Effects of resource availability and climate on the diversity of wood-decaying fungi. Journal of Ecology, 98, 822-832. https://doi.org/10.1111/j.1365-2745. 2010.01669.x

Boddy, L., Büntgen, U., Egli, S., Gange, A. C., Heegaard, E., Kirk, P. M., . . Kauserud, H. (2014). Climate variation effects on fungal fruiting. Fungal Ecology, 10, 20-33. https://doi.org/10.1016/j.funeco.2013.10.006

Bueno, C. G., Moora, M., Gerz, M., Davison, J., Öpik, M., Pärtel, M., .. Zobel, M. (2017). Plant mycorrhizal status, but not type, shifts with latitude and elevation in Europe. Global Ecology and Biogeography, 26, 690-699. https://doi.org/10.1111/geb.12582

Büntgen, U., Kauserud, H., \& Egli, S. (2012). Linking climate variability to mushroom productivity and phenology. Frontiers in Ecology and the Environment, 10, 14-19. https://doi.org/10.1890/110064

Clemmensen, K. E., Bahr, A., Ovaskainen, O., Dahlberg, A., Ekblad, A., Wallander, H., ... Lindahl, B. D. (2013). Roots and associated fungi drive long-term carbon sequestration in boreal forest. Science, 339, 1615-1618. https://doi.org/10.1126/science.1231923

de Vries, W., Solberg, S., Dobbertin, M., Sterba, H., Laubhann, D., Van Oijen, M., ... Reinds, G. J. (2009). The impact of nitrogen deposition on carbon sequestration by European forests and heathlands. Forest Ecology and Management, 258, 1814-1823. https://doi.org/10.1016/ j.foreco.2009.02.034

Dormann, C. F., Elith, J., Bacher, S., Buchmann, C., Carl, G., Carré, G., ... Münkemüller, T. (2013). Collinearity: A review of methods to deal with it and a simulation study evaluating their performance. Ecography, 36, 27-46. https://doi.org/10.1111/j.1600-0587.2012.07348.x

Engler, R., Randin, C. F., Thuiller, W., Dullinger, S., Zimmermann, N. E., Araújo, M. B., ... Choler, P. (2011). 21st century climate change threatens mountain flora unequally across Europe. Global Change Biology, 17, 2330-2341. https://doi.org/10.1111/j.1365-2486.2010. 02393.x

Gange, A. C., Heegaard, E., Boddy, L., Andrew, C., Kirk, P., Halvorsen, R., ... Kauserud, H. (2017). Trait-dependent distributional shifts in fruiting of common British fungi. Ecography, 40, 51-61. https://doi.org/ 10.1111/ecog.03233

Grytnes, J. A., Kapfer, J., Jurasinski, G., Birks, H. H., Henriksen, H., Klanderud, K., \& Birks, H. J. B. (2014). Identifying the driving factors behind observed elevational range shifts on European mountains. Global Ecology and Biogeography, 23, 876-884. https://doi.org/10. 1111/geb.12170

Halbritter, A. H., Alexander, J. M., Edwards, P. J., \& Billeter, R. (2013). How comparable are species distributions along elevational and latitudinal climate gradients? Global Ecology and Biogeography, 22, 1228 1237. https://doi.org/10.1111/geb.12066

Halme, P., Heilmann-Clausen, J., Rämä, T., Kosonen, T., \& Kunttu, P. (2012). Monitoring fungal biodiversity-towards an integrated approach. Fungal Ecology, 5, 750-758. https://doi.org/10.1016/j.fu neco.2012.05.005

Heilmann-Clausen, J., Aude, E., Dort, K., Christensen, M., Piltaver, A., Veerkamp, M., ... Òdor, P. (2014). Communities of wood-inhabiting bryophytes and fungi on dead beech logs in Europe-reflecting substrate quality or shaped by climate and forest conditions? Journal of Biogeography, 41, 2269-2282. https://doi.org/10.1111/jbi.12388

Heilmann-Clausen, J., Barron, E. S., Boddy, L., Dahlberg, A., Griffith, G. W., Nordén, J., ... Halme, P. (2014). A fungal perspective on conservation biology. Conservation Biology, 29, 61-68.
Heilmann-Clausen, J., Maruyama, P. K., Bruun, H. H., Dimitrov, D., Læssøe, T., Frøslev, T. G., \& Dalsgaard, B. (2016). Citizen science data reveal ecological, historical and evolutionary factors shaping interactions between woody hosts and wood-inhabiting fungi. New Phytologist, 212, 1072-1082. https://doi.org/10.1111/nph.14194

Hijmans, R. J., Cameron, S. E., Parra, J. L., Jones, P. G., \& Jarvis, A. (2005). Very high resolution interpolated climate surfaces for global land areas. International Journal of Climatology, 25, 1965-1978. https://doi.org/10.1002/(ISSN)1097-0088

Kauserud, H., Heegaard, E., Büntgen, U., Halvorsen, R., Egli, S., Senn-Irlet, B., ... Høiland, K. (2012). Warming-induced shift in European mushroom fruiting phenology. Proceedings of the National Academy of Sciences of the USA, 109, 14488-14493. https://doi.org/10.1073/pna s.1200789109

Kauserud, H., Heegaard, E., Semenov, M. A., Boddy, L., Halvorsen, R., Stige, L. C., ... Stenseth, N. C. (2010). Climate change and springfruiting fungi. Proceedings of the Royal Society of London B: Biological Sciences, 277, 1169-1177. https://doi.org/10.1098/rspb.2009.1537

Kauserud, H., Stige, L. C., Vik, J. O., Økland, R. H., Høiland, K., \& Stenseth, N. C. (2008). Mushroom fruiting and climate change. Proceedings of the National Academy of Sciences, 105, 3811-3814. https://doi. org/10.1073/pnas.0709037105

Kyaschenko, J., Clemmensen, K. E., Karltun, E., \& Lindahl, B. D. (2017). Below-ground organic matter accumulation along a boreal forest fertility gradient relates to guild interaction within fungal communities. Ecology Letters, 20, 1546-1555. https://doi.org/10.1111/ele.12862

Lilleskov, E. A., Fahey, T. J., \& Lovett, G. M. (2001). Ectomycorrhizal fungal aboveground community change over an atmospheric nitrogen deposition gradient. Ecological Applications, 11, 397-410. https://doi. org/10.1890/1051-0761(2001)011[0397:EFACCO]2.0.CO;2

Liu, H. Y., Økland, T., Halvorsen, R., Gao, J. X., Liu, Q. R., Eilertsen, O., \& Bratli, H. (2008). Gradient analyses of forests ground vegetation and its relationships to environmental variables in five subtropical forest areas S and SW China. Sommerfeltia, 32, 1e196.

Mahecha, M. D., Martínez, A., Lischeid, G., \& Beck, E. (2007). Nonlinear dimensionality reduction: Alternative ordination approaches for extracting and visualizing biodiversity patterns in tropical montane forest vegetation data. Ecological Informatics, 2, 138e149.

Martiny, J. B. H., Bohannan, B. J., Brown, J. H., Colwell, R. K., Fuhrman, J. A., Green, J. L., ... Staley, J. T. (2006). Microbial biogeography: Putting microorganisms on the map. Nature Reviews Microbiology, 4, 102-112. https://doi.org/10.1038/nrmicro1341

Meiser, A., Bálint, M., \& Schmitt, I. (2014). Meta-analysis of deepsequenced fungal communities indicates limited taxon sharing between studies and the presence of biogeographic patterns. New Phytologist, 201, 623-635. https://doi.org/10.1111/nph.12532

Naff, C. S., Darcy, J. L., \& Schmidt, S. K. (2013). Phylogeny and biogeography of an uncultured clade of snow chytrids. Environmental Microbiology, 15, 2672-2680.

Nielsen, A., Yoccoz, N. G., Steinheim, G., Storvik, G. O., Rekdal, Y., Angeloff, M., ... Mysterud, A. (2012). Are responses of herbivores to environmental variability spatially consistent in alpine ecosystems? Global Change Biology, 18, 3050-3062. https://doi.org/10.1111/j.13652486.2012.02733.x

Nordén, J., Penttilä, R., Siitonen, J., Tomppo, E., \& Ovaskainen, O. (2013). Specialist species of wood-inhabiting fungi struggle while generalists thrive in fragmented boreal forests. Journal of Ecology, 101, 701-712. https://doi.org/10.1111/1365-2745.12085

$\varnothing$ Øland, R. H. (1996). Are ordination and constrained ordination alternative or complementary strategies in general ecological studies? Journal of Vegetation Science, 7, 289e292.

Oksanen, J., Blanchet, F. G., Kindt, R., Legendre, P., Minchin, P. R., O'Hara, R. B., ... Wagner, H. (2013). Vegan: Community Ecology Package. R Package Version 2.0-9. Retrieved from http://CRAN.R-pro ject.org/package1/4vegan 
Pellissier, L., Pinto-Figueroa, E., Niculita-Hirzel, H., Moora, M., Villard, L., Goudet, J., .. Guisan, A. (2013). Plant species distributions along environmental gradients: Do belowground interactions with fungi matter? Frontiers in Plant Science, 4, 500.

Peter, M., Ayer, F., \& Egli, S. (2001). Nitrogen addition in a Norway spruce stand altered macromycete sporocarp production and belowground ectomycorrhizal species composition. New Phytologist, 149, 311-325. https://doi.org/10.1046/j.1469-8137.2001.00030.x

Pettorelli, N., Vik, J. O., Mysterud, A., Gaillard, J. M., Tucker, C. J., \& Stenseth, N. C. (2005). Using the satellite-derived NDVI to assess ecological responses to environmental change. Trends in Ecology \& Evolution, 20, 503-510. https://doi.org/10.1016/j.tree.2005.05.011

Rinaldi, A. C., Comandini, O., \& Kuyper, T. W. (2008). Ectomycorrhizal fungal diversity: Seperating the wheat from the chaff. Fungal Diversity, 33, 1-45.

Rineau, F., \& Garbaye, J. (2009). Effects of liming on ectomycorrhizal community structure in relation to soil horizons and tree hosts. Fungal Ecology, 2, 103-109. https://doi.org/10.1016/j.funeco.2009.01. 006

Siefert, A., Lesser, M. R., \& Fridley, J. D. (2015). How do climate and dispersal traits limit ranges of tree species along latitudinal and elevational gradients? Global Ecology and Biogeography, 24, 581-593. https://doi.org/10.1111/geb.12287

Soudzilovskaia, N. A., Douma, J. C., Akhmetzhanova, A. A., Bodegom, P. M., Cornwell, W. K., Moens, E. J., ... Cornelissen, J. H. (2015). Global patterns of plant root colonization intensity by mycorrhizal fungi explained by climate and soil chemistry. Global Ecology and Biogeography, 24, 371-382. https://doi.org/10.1111/geb.12272

Swaty, R., Michael, H. M., Deckert, R., \& Gehring, C. A. (2016). Mapping the potential mycorrhizal associations of the conterminous United States of America. Fungal Ecology, 24, 139-147. https://doi.org/10. 1016/j.funeco.2016.05.005

Taylor, D. L., Hollingsworth, T. N., McFarland, J. W., Lennon, N. J., Nusbaum, C., \& Ruess, R. W. (2014). A first comprehensive census of fungi in soil reveals both hyperdiversity and fine-scale niche partitioning. Ecological Monographs, 84, 3-20. https://doi.org/10.1890/121693.1

Tedersoo, L., Bahram, M., Põlme, S., Kõljalg, U., Yorou, N. S., Wijesundera, R., ... Abarenkov, K. (2014). Global diversity and geography of soil fungi. Science, 346, 1256688. https://doi.org/10.1126/science. 1256688

Tedersoo, L., Bahram, M., Ryberg, M., Otsing, E., Kõljalg, U., \& Abarenkov, K. (2014). Global biogeography of the ectomycorrhizal/sebacina lineage (Fungi, Sebacinales) as revealed from comparative phylogenetic analyses. Molecular Ecology, 23, 4168-4183. https://doi.org/10. 1111/mec.12849

Tedersoo, L., Bahram, M., Toots, M., Diedhiou, A. G., Henkel, T. W., Kjøller, R., ... Polme, S. (2012). Towards global patterns in the diversity and community structure of ectomycorrhizal fungi. Molecular Ecology, 21, 4160-4170. https://doi.org/10.1111/j.1365-294X.2012. 05602.x

Tedersoo, L., \& Smith, M. E. (2013). Lineages of ectomycorrhizal fungi revisited: Foraging strategies and novel lineages revealed by sequences from belowground. Fungal Biology Reviews, 27, 83-99. https://doi.org/10.1016/j.fbr.2013.09.001

Tenenbaum, J. B., De Silva, V., \& Langford, J. C. (2000). A global geometric framework for nonlinear dimensionality reduction. Science, 290, $2319 \mathrm{e} 2323$.

Unterseher, M., Jumpponen, A. R. I., Oepik, M., Tedersoo, L., Moora, M., Dormann, C. F., \& Schnittler, M. (2011). Species abundance distributions and richness estimations in fungal metagenomics-lessons learned from community ecology. Molecular Ecology, 20, 275285. https://doi.org/10.1111/j.1365-294X.2010.04948.x

van Son, T. C., \& Halvorsen, R. (2014). Multiple parallel ordinations: The importance of choice of ordination method and weighting of species abundance data. Sommerfeltia, 37, 1-37. https://doi.org/10. 2478/som-2014-0001

van Strien, A. J., Boomsluiter, M., Noordeloos, M. E., Verweij, R. J., \& Kuyper, T. W. (2017). Woodland ectomycorrhizal fungi benefit from large-scale reduction of nitrogen deposition in the Netherlands. Journal of Applied Ecology, 55, 290-298.

Venables, W. N., \& Ripley, B. D. (2002). Modern applied statistics with $S$ (4th ed.). New York, NY: Springer. https://doi.org/10.1007/978-0387-21706-2

Wood, S. N. (2006). Generalized Additive Models, an Introduction with R. London: Chapmann and Hall.

\section{BIOSKETCH}

Dr. Andrew was a postdoctoral researcher for the duration of this project. The work presented in this manuscript represents a component of the ClimFun project, an international collaboration that united national-scale fruit body data sets for macroecological investigations of fungi in relation to environmental drivers, especially global change components.

Author contributions: H.K., C.A. and E.H. conceived the main ideas; C.A. prepared the data with data access and rights provided via A.C.G., B.S.I., C.B., I.K.G., J.H.C., P.M.K., S.E. and T.W.K.; C.A., R.H. and E.H. analysed the data; C.A. led the writing; and all coauthors contributed to wide-range general discussion and interpretation during the project, along with manuscript edits: R.H., E.H., T.W.K., J.H.C., I.K.G., C.B., S.E., A.C.G., K.H., P.M.K., B.S.I., L.B., U.B. and H.K.

\section{SUPPORTING INFORMATION}

Additional supporting information may be found online in the Supporting Information section at the end of the article.

How to cite this article: Andrew C, Halvorsen R, Heegaard E, et al. Continental-scale macrofungal assemblage patterns correlate with climate, soil carbon and nitrogen deposition. J Biogeogr. 2018;45:1942-1953. https://doi.org/10.1111/ $\underline{\text { jbi.13374 }}$ 